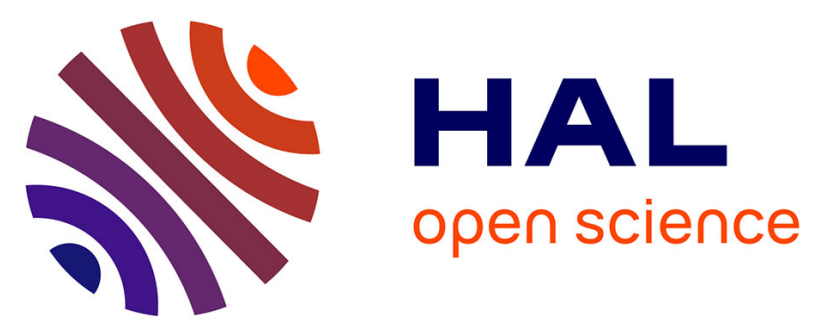

\title{
A Conceptual Digital Assistance System Supporting Manual Changeovers in High-Variety Production
}

Rasmus Andersen, Christopher Ketelsen, Kjeld Nielsen, Ann-Louise Andersen, Thomas D. Brunoe, Sofie Bech

\section{- To cite this version:}

Rasmus Andersen, Christopher Ketelsen, Kjeld Nielsen, Ann-Louise Andersen, Thomas D. Brunoe, et al.. A Conceptual Digital Assistance System Supporting Manual Changeovers in High-Variety Production. IFIP International Conference on Advances in Production Management Systems (APMS), Aug 2018, Seoul, South Korea. pp.449-455, 10.1007/978-3-319-99707-0_56 . hal-02177867

\section{HAL Id: hal-02177867 https://hal.inria.fr/hal-02177867}

Submitted on 9 Jul 2019

HAL is a multi-disciplinary open access archive for the deposit and dissemination of scientific research documents, whether they are published or not. The documents may come from teaching and research institutions in France or abroad, or from public or private research centers.
L'archive ouverte pluridisciplinaire HAL, est destinée au dépôt et à la diffusion de documents scientifiques de niveau recherche, publiés ou non, émanant des établissements d'enseignement et de recherche français ou étrangers, des laboratoires publics ou privés.

\section{(c)(1)}

Distributed under a Creative Commons Attribution| 4.0 International License 


\title{
A Conceptual Digital Assistance System Supporting Manual Changeovers in High-Variety Production
}

\author{
Rasmus Andersen ${ }^{(\text {四 }}$ [0000-0001-6788-8217], Christopher Ketelsen ${ }^{[0000-0003-1735-4617]}$, Kjeld \\ Nielsen $^{[0000-0002-3720-167 X]}$, Ann-Louise Andersen ${ }^{[0000-0002-7923-6301]}$, Thomas D. Bru- \\ noe ${ }^{[0000-0002-9847-6562]}$, and Sofie Bech \\ Department of Materials and Production, Aalborg University, Denmark \\ therasmusandersen@gmail.com
}

\begin{abstract}
The advent of production strategies such as Mass Customization and Changeable Manufacturing requires that production systems be increasingly flexible towards diverse customer needs. Although humans remain the most flexible entity in modern production systems, the increasing complexity of these systems presents a challenge for the operators with regards to remaining efficient. Research related to Industry 4.0 has promoted the application of digital assistance systems, as a method of augmenting human operators to handle the complexity of these production systems better. However, no digital assistance system that supports human operators in performing manual changeover operations in complex production systems has been identified. This paper, therefore, presents a conceptual digital assistance system, which utilizes information about two consecutive production configurations, and processes this data through an algorithm, to determine which specific changeover operations are required to perform a changeover most efficiently. Potentials of implementing the proposed digital assistance system are briefly introduced, and topics for further research are outlined.
\end{abstract}

Keywords: Digital Assistance System, Changeover Ability, Changeability, Changeable Manufacturing, Mass Customization

\section{Introduction}

The production strategy of Mass Customization, which focuses on offering customers individualized products at near mass production costs, has become increasingly relevant since the 1980's, where a shift in market circumstances has challenged the practice of traditional mass producers in many industries [1]. To cope with these changed circumstances, many companies see the ability to adapt to changes in production mix and volume as providing superior competitive advantages [2]. From a production perspective, one of the enablers of mass customization concerns robust processes, which can be achieved through changeability. In seminal works on the subject, changeability is defined as " $[\ldots]$ the characteristics to accomplish early and foresighted adjustments of the factory's structures and processes on all levels, due to change impulses, economi- 
cally." [3] Although changeability must permeate all levels of the factory, its foundation constitutes the workstation level performing the actual operations [4], meaning that to obtain changeable production systems, the individual stations comprising the system must themselves be changeable. Enablers of changeability on the station level are changeover ability, which relates to the individual work station's ability to process a given part or component as efficiently as possible in terms of both time and resources [3]. Although changeover ability can be facilitated using automation [3] most changeovers are still performed by human operators [5]. The increase in product variety and simultaneous decrease in production batch sizes, resulting from introducing Mass Customization to a production system, has a negative effect on the learning and memory performance of the human operators [6, 7]. Besides these impacts, six additional challenges for human operators in relation to changeover ability have been identified [8]. Based on a review of existing literature Ketelsen et al. [8] concluded that there are two overall gaps concerning solutions to support human operators. These are related to overcoming the negative effects of increased task variety and decreased task repetition. Research related to human operators in Industry 4.0 points towards utilization of digital information [9] or assistance systems [10-12] as solutions for augmenting human operators to better manage the increasing complexity of modern production systems. Assistance systems have been classified as one of five major research branches within Industry 4.0 [13]. However, despite this recognition, no solutions have been identified, which directly address the issue of assisting human operators in efficiently handling manual changeover tasks in high-variety settings. Failing to support operators cognitively results in a hampered ability to deliver a high variety of products cost effectively [8], which in turn decreases the competitiveness of a company. Recognizing this gap, this paper presents a concept for a digital assistance system designed to support human operators in efficiently carrying out highly varying manual changeover tasks. The remainder of the article is structured as follows; Section 2 introduces digital assistance systems in the context of high-variety manufacturing. Then, Section 3 presents the conceptual design and functioning of the proposed digital assistance system. Section 4 discusses potential improvements to be gained from implementing the proposed assistance system. Finally, Section 5 points out directions for further research related to the development of the digital assistance system.

\section{Digital Assistance Systems}

Although fully automated and autonomous production systems are gaining increasing interest, this does not translate to the complete exclusion of humans from the production system [14]. Despite advances in manufacturing technology, the human is still recognized as the most flexible entity in a production system [11]. However, as outlined above, human operators are still subject to certain limitations mainly related to their cognitive abilities. Together with the increased complexity of modern production systems, the need to support human operators in their work tasks is, therefore, essential $[10,12,13,15]$. In the Operator 4.0 typology proposed by Romero et al. [15] one of the 
eight archetypes of the typology is the "Augmented Operator". This archetype encompasses the use of digital assistance systems as a means of offloading cognitive work for human operators. Specifically, this is realized through digital assistance systems utilizing augmented reality as a facilitator for integrating humans and computer systems on the factory floor. [15] Augmenting operators can be accomplished using mobile smart devices [11] that are connected to different data sources within the factory [13], and can thus be considered as a type of cyber-physical system [7]. A digital assistance system relies on the ability to collect and display data from multiple data sources within the company [13] in order to present these to the operators in an efficient and easily understandable way [11]. This involves catering to the individual preferences of human operators $[10,11]$ by designing the digital assistance system to support multi-modal information presentation [12]. Furthermore, to increase the usability of the digital assistance system, it is suggested that design of the user interface is inspired by apps for smartphones and tablets since most operators will be familiar with these interfaces [11]. Reviewing literature on digital assistance systems have produced several solutions related to augmenting human operators in a product assembly scenario (e.g. [7, 12]). However, no literature was identified, which addresses this issue in a manual production changeover scenario.

\section{Conceptual Assistance System in Support of Manual Changeover Operations}

The purpose of the proposed digital assistance system is to support human operators in performing complex changeovers, whether it is on individual workstations or entire production lines, in order to achieve changeability. Fig. 1, left side, presents a flowchart illustrating the functioning of the digital assistance system in transforming individual production configurations into actionable changeover tasks. First, information about the next product changeover is obtained. Then, based on this information, the corresponding production configuration for each of the products is extracted from a database. Hereafter, an algorithm analyzes the two production configurations and filters out any identical rows, representing specific configurations of settings, across them. This produces a new table containing only the actual changes that must be made to the current production configuration to change over to the next, as per the production plan. The changeover operations are then analyzed by a second algorithm, which matches sets of individual changeover operations with continuous improvement initiatives logged in another database. These initiatives are then appended to the relevant changeover operation. The result is then visualized for the human operators performing the changeover.

Following this brief introduction to the functioning of the digital assistance system, the aspects of collecting, processing, and presenting the data for the digital assistance system is explained in more detail. 


\subsection{Information Gathering}

The digital assistance system relies on data from three different sources, which are the production planning module in the enterprise resource planning (ERP) system, the production configuration database, and the changeover instruction database. The production planning module in the ERP system provides the digital assistance system with the current production plan, from which the unique product IDs for the product being changed from as well as the product being changed to can be obtained. The instruction database contains structured data about all changeover instructions for existing product variations. This database is updated through a database interface where changes to existing instructions are applied centrally and then automatically propagate to the changeover instructions for all related product variants. The database interface also allows the creation of changeover instructions for new product variants.
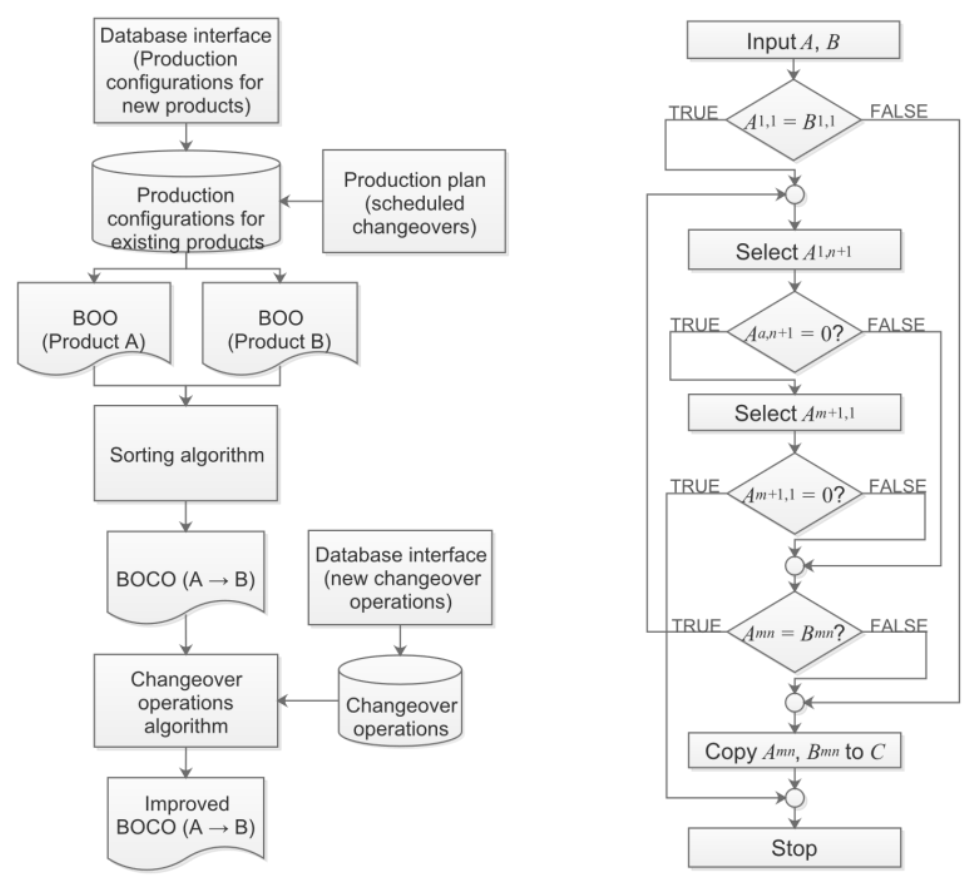

Fig. 1. (Left side) Flowchart of the digital assistance system. (Right side) Sorting and filtering algorithm illustrated following drawing style of Tausworthe [16].

\subsection{Information Processing}

Part of augmenting human operators through the digital assistance system is done by processing data to deliver context-specific and timely data. The data processing is performed by algorithms, which provide a means of computing a solution to a problem, based on an explicitly defined computational process [17]. The first algorithm that is 
applied to the data is concerned with sorting and filtering the production configuration settings based on both the product that is changed from, as well as the product that is changed to. The purpose of the algorithm is to filter out any setup constants across the two setup configurations. This leaves only the relevant changeover tasks to be performed for that specific changeover. Fig. 1, right side, presents a flowchart detailing the functioning of the algorithm, using symbols and drawing styles following Tausworthe [16]. First, the algorithm loads the two matrices $A$ and $B$, containing the production configurations or bill-of-operations (BOO) for the product being changed from and the product being changed to, respectively. Then, the algorithm successively evaluates each row, $m$, and all variables, $n$, in $A$ against its corresponding counterpart $B$. Thus, for every row the algorithm evaluates the value of $A_{n m}$ against the value of $B_{m n}$. If the evaluation returns TRUE, the algorithm registered a constant prompting it to proceed to the next variable. The algorithm proceeds by evaluating every remaining variable in the current row, and if no FALSE conditions are returned, the row is marked as a constant across the two production configurations, thereby prompting the algorithm to ignore it and proceed to the next row. However, if any of the variable evaluations returns a FALSE, the algorithm copies the two configurations to a new matrix $C$. This behavior is performed successively until all rows have been processed, after which the algorithm stops. Hereafter, the individual changeover operations are applied to the sets of production configurations, forming a document containing all the operations necessary to perform a changeover between two given production setup configurations, as illustrated in Fig. 1, left side. It is proposed that the resulting document is referred to as the bill-of-changeover-operations (BOCO).

Extending the processing power of the digital assistance system further, machine learning could be utilized by the system to acquire knowledge of how to best present information to the users based on their previous interaction with the system. This would provide the assistance system with the ability to present varying detail levels of changeover instructions to the operators based on their experience or based on data analyses of, e.g., error prone changeover operations. [18]

\subsection{Information Presentation}

The final aspect of the digital assistance system is the user interface, which is the part of the system that the human operator will interact with. It is, therefore, an essential aspect of a digital assistance system, as even an assistance system with a powerful data processing ability will be of little use if this data cannot be communicated efficiently to the operator. It is proposed that the digital assistance system interacts with users through a touchscreen interface on a tablet, as it is expected that smaller smart devices will have insufficient display size to communicate the processed changeover instructions efficiently. Alternatively, with the prevalence of augmented reality technology it has been proposed that an even higher level of digital assistance would be provided by progressing from tablet-based instructions to augmented reality glasses [19]. However, regardless of the choice of smart devices to visualize changeover instructions, Mattsson et al. [20] found that humans prefer graphical rather than text-based instructions for assembly work. The changeover instructions are, therefore, to be presented primarily 
as graphical entities, with the option of switching between multiple modes of graphics, such as animations or figures.

\section{Conclusion}

In this paper, a conceptual digital assistance system supporting manual changeovers in high-variety production was proposed to increase changeability in production. Since the digital assistance system is still in a conceptual stage, there are not yet actual results from implementation to report. However, literature presents several aspects related to production performance, where a digital assistance system is expected to deliver improved results. Hold et al. [7] state that the primary purpose of a digital assistance system is to improve productivity, which in turn results in a positive influence on key performance indicators like the overall equipment effectiveness [13]. More specifically, for the described conceptual digital assistance system, the general benefits mentioned by Romero et al. [15] may translate into faster and more consistent changeover times. This may be attributed to the reduced cognitive load on the operators caused by the focused changeover instructions. Furthermore, a digital assistance system may reduce errors made by operators [15] by assisting them with choosing the correct setups and tools [7]. The authors expect that improvements of the same parameters are possible through the implementation of the proposed digital assistance system as well. Besides the potential benefits, implementing the conceptual digital assistance system in a highvariety production setting may incur extensive costs related to the production of the required changeover instructions. However, research suggests the possibility of using reconfigurable instruction sequences to facilitate cost-effective, high-variety instructions [21].

\section{$5 \quad$ Further Research}

For the conceptual digital assistance system introduced in this paper to fulfill the abovedescribed potentials, additional work is needed. First, further research into how the briefly described continuous improvement element of the system should be designed is required. This is particularly important as the ability of the operators to share experiences and best-practices with their colleagues is essential for the performance of the production system [11]. Once a prototype of the digital assistance system has been finished, real-life experiments in a production company are required to validate the potentials of the digital assistance system regarding increasing production performance. Looking even further into the future, the potential of utilizing changeover data from the digital assistance system to optimize production planning is seen as a relevant research topic.

\section{References}

1. Koren, Y.: Reconfigurable Manufacturing Systems. In: The Global Manufacturing 
Revolution, 1st ed., pp. 227-252. John Wiley \& Sons, Inc., Hoboken, NJ, USA (2010).

2. Andersen, A., Larsen, J.K., Brunoe, T.D., et al.: Exploring Requirements and Implementation of Changeability and Reconfigurability in Danish Manufacturing. In: 51st CIRP Conference on Manufacturing Systems Exploring, pp. 665-670. Elsevier B.V. (2018).

3. ElMaraghy, H. A., Wiendahl, H-P.: Changeability - An Introduction. In: ElMaraghy, H. A. (ed) Changeable and Reconfigurable Manufacturing Systems, pp. 3-24. Springer London, London (2009).

4. Owen, G.W., Matthews, J., McIntosh, R.I., Culley, S.J.: Design for Changeover (DFC): Enabling Flexible and Highly Responsive Manufacturing. In: Fogliatto, F.S., da Silveira, G.J.C. (eds.) Mass Customization: Engineering and Managing Global Operations, pp. 247-273. Springer London, London (2011).

5. Brunoe, T.D., Andersen, A-L., Nielsen, K.: Reconfigurable Manufacturing Systems in Small and Medium Enterprises. In: Bellemare, J., Carrier, S., Nielsen, K., Piller, F.T. (eds.) Managing Complexity, pp. 205-213. Springer International Publishing, Cham (2017).

6. Jaber, M.Y., Bonney, M.: Lot sizing with learning and forgetting in set-ups and in product quality. Int J Prod Econ 83, 95-111 (2003).

7. Hold, P., Erol, S., Reisinger, G., Sihn, W.: Planning and Evaluation of Digital Assistance Systems. Procedia Manuf 9, 143-150 (2017).

8. Ketelsen, C., Andersen, R., Nielsen, K., et al.: A literature review on human changeover ability in high-variety production. In: Advances in Production Management System 2018 (2018) (Submitted).

9. Dean, P.R., Tu, Y.L., Xue, D.: An information system for one-of-a-kind production. Int J Prod Res 47, 1071-1087 (2009).

10. Lall, M., Torvatn, H., Seim, E.A.: Towards Industry 4.0: Increased Need for Situational Awareness on the Shop Floor. In: Lödding, H., Riedel, R., Thoben, K-D., et al. (eds.) Advances in Production Management Systems. The Path to Intelligent, Collaborative and Sustainable Manufacturing. Springer, pp. 322 - 329. International Publishing, Cham (2017).

11. Gorecky, D., Schmitt, M., Loskyll, M., Zühlke, D.: Human-machine-interaction in the industry 4.0 era. Proc - 2014 12th IEEE Int Conf Ind Informatics, INDIN 2014, pp. 289 294 (2014).

12. Claeys, A., Hoedt, S., Van Landeghem, H., Cottyn, J.: Generic Model for Managing Context-Aware Assembly Instructions. IFAC-PapersOnLine 49, 1181-1186 (2016).

13. Prinz, C., Kreimeier, D., Kuhlenkötter, B.: Implementation of a Learning Environment for an Industrie 4.0 Assistance System to Improve the Overall Equipment Effectiveness. Procedia Manuf 9, 159-166 (2017).

14. Al-Ani, A.: CPS and the Worker: Reorientation and Requalification? In: Jeschke, S., Brecher, C., Song, H., Rawat, D.B. (eds.) Industrial Internet of Things: Cybermanufacturing Systems, pp.563 - 574. Springer International Publishing, Cham (2017).

15. Romero, D., Stahre, J., Wuest, T., et al.: Towards an Operator 4.0 Typology: A HumanCentric Perspective on the Fourth Industrial Revolution Technologies. CIE 2016 46th Int Conf Comput Ind Eng, 1-11 (2017). 
16. Tausworthe, R.C.: Standardized development of computer software (1977).

17. Cormen, T.H., Leiserson, C.E., Rivest, R.L., Stein, C.: Introduction to Algorithms. MIT Press (2001).

18. Schuhmacher, J.: Machine Learning for User Learning. Titel Mensch und Comput 1013 (2017).

19. Fischer, H., Engler, M., Sauer, S.: A Human-Centered Perspective on Software Quality: Acceptance Criteria for Work 4.0. In: Marcus, A., Wang, W. (eds.) Design, User Experience, and Usability: Theory, Methodology, and Management, pp. 570-583 Springer International Publishing, Cham (2017).

20. Mattsson, S., Fast-Berglund, A., Li, D.: Evaluation of Guidelines for Assembly Instructions. IFAC-PapersOnLine 49, 209-214 (2016).

21. Reisinger, G., Komenda, T., Hold, P., Sihn, W.: A Concept towards Automated DataDriven Reconfiguration of Digital Assistance Systems, Procedia Manuf 23, 99-104 (2018). 